\title{
SIMULATION EXPERIMENTS ON THE MIGRATION OF GAMMARUS ZADDACHI AND GAMMARUS CHEVREUXI
}

\author{
by \\ H. B. GIRISCH \& H. G. DENNERT \\ Institute of Taxonomic Zoology (Zoölogisch Museum), University of Amsterdam, \\ The Netherlands
}

\begin{abstract}
The migratory activity of Gammarus zaddachi and Gammarus chevreuxi is investigated in a current chamber, in which a tidal cycle can be simulated.

In fresh running water the number of animals drifting with the current is of about the same magnitude as the number of animals actively swimming against the current.

A diurnal periodicity is recorded in the migratory activity. The migratory activity is influenced by the population density and the food supply.

In the current chamber a tidal cycle can be simulated by varying the factors current velocity, current direction, salinity, and temperature. The combination of a decrease in current velocity, followed by a slow current in the opposite direction, an increase in the salinity, and a rise in the temperature of the medium causes a significant increase in the activity of both species investigated. An increase in only one of the environmental factors mentioned above can also produce an increase in the migratory activity, but less pronounced than when all the factors coordinate in simulating a complete tidal cycle.

Both $G$. zaddachi and $G$. chevreuxi react in a similar way on the simulation of a tidal cycle. In both species no great differences have been found between juveniles and adults with regard to the migratory activity.

The results of the simulation experiments are discussed in connection with the migration cycles of $G$. zaddachi and $G$. chevreuxi as recorded in the field.
\end{abstract}

\section{INTRODUCTION}

The migration of gammarids in streams has been the subject of a number of publications, recently reviewed by Waters (1969) and Meijering (1972). Much less work has been done on simulation experiments of the migration of Gammarus. Hughes (1970), Vobis (1972), and Meijering (1972) started laboratory experiments on this subject, but they worked on the migration of freshwater gammarids, viz. G. pulex (Linnaeus, 1758), G. fossarum Koch in Panzer, 1836, and G. roeseli (Gervais, 1835).
The migration of brackish water gammarids has been studied by Dennert et al. (1969), Dennert \& Van Maren (1974), and Girisch et al. (1974). It was shown that G. zaddachi Sexton, 1912, and G. chevreuxi Sexton, 1913, both have a diurnal activity pattern, the activity peak occurring at night. Also in both species migratory activity was recorded in catadromous and in anadromous direction, the migration in upstream direction being recorded only at high water spring tide.

Dennert et al. (1969) and Girisch et al. (1974) postulated the hypothesis, that $G$. zaddachi and G. chevreuxi show a difference in behaviour between adults and juveniles, when the migratory activity of these groups are compared.

In the case of $G$. zaddachi the juveniles are supposed to migrate mainly in upstream direction, while the preadults and adults migrate mainly in downstream direction. The migration cycle as recorded in two French streams, viz. La Slack, Pasde-Calais (Dennert et al., 1969; Dennert \& Van Maren, 1974) and Le Dourduff, Finistère-Nord (Girisch et al., 1974), could be correlated with the reproductive cycle of $G$. zaddachi, and with certain fysicochemical parameters such as temperature, current direction, and salinity changes.

In the case of $G$. chevreuxi we have to do with a more complex situation. Girisch et al. (1974: fig. 29) give a recapitulation of its migration cycle. Upstream movements occur all year round, except in the summer months. The activity peak for the upstream migration falls in September, October and November, when adults and juveniles migrate from the estuary to the limnic part of the river. The preadults, originating from these juveniles, migrate in winter (December, January, February) back to the estuary. Apart from these main activity peaks, smaller numbers of animals can be 
Table I. Origin of the experimental populations. Also it is indicated with which samples of Dennert et al., 1969 (in the case of G. zaddachi) or of Girisch et al., 1974 (in the case of G. chevreuxi) the experimental populations can be compared.

\begin{tabular}{|c|c|c|c|c|c|c|c|}
\hline Species & $\begin{array}{l}\text { Experimental } \\
\text { population }\end{array}$ & $\begin{array}{l}\text { Number } \\
\text { of } \\
\text { animals }\end{array}$ & Locality & $\begin{array}{l}\text { Catching date } \\
\text { (day, month, } \\
\text { year) }\end{array}$ & $\begin{array}{l}\text { Migration } \\
\text { direction }\end{array}$ & $\begin{array}{l}\text { Population } \\
\text { composition } \\
\text { comparable } \\
\text { with }\end{array}$ & $\begin{array}{l}\text { Population } \\
\text { composition } \\
\text { see fig. }\end{array}$ \\
\hline G. zaddachi & $\begin{array}{l}\mathbf{A} \\
\mathbf{B}\end{array}$ & $\begin{array}{r}90 \\
100\end{array}$ & $\begin{array}{l}\text { Slack, } \\
\text { sta. I }\end{array}$ & $24-11-1973$ & up & - & - \\
\hline G. zaddachi & $\begin{array}{l}\text { C } \\
\text { D } \\
E\end{array}$ & $\begin{array}{r}100 \\
117 \\
50\end{array}$ & $\begin{array}{l}\text { Slack, } \\
\text { sta. I \& II }\end{array}$ & 10- $1-1974$ & down & $\begin{array}{l}\text { downstreamers, } \\
\text { Slack, sta. I } \\
\text { Dec. } 1967\end{array}$ & 1 \\
\hline G. zaddachi & $\mathbf{F}$ & 103 & North Sea Canal & 5- 4-1974 & - & - & 2 \\
\hline G. chevreuxi & G & 340 & $\begin{array}{l}\text { Dourduff, } \\
\text { sta. II }\end{array}$ & 24- $2-1974$ & up & $\begin{array}{l}\text { downstreamers, } \\
\text { Dourduff, } \\
\text { sta. II } \\
\text { March } 1972\end{array}$ & 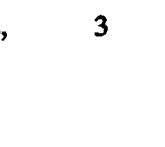 \\
\hline G. chevreuxi & $\mathbf{H}$ & 532 & $\begin{array}{l}\text { Dourduff, } \\
\text { sta. II } \\
\text { III \& IV } \text { IV }^{1}\end{array}$ & $\begin{array}{l}23-2-1974 \\
27-2-1974\end{array}$ & down $^{1}$ ) & $\begin{array}{l}\text { downstreamers, } \\
\text { Dourduff, } \\
\text { sta. II } \\
\text { Feb. } 1972\end{array}$ & 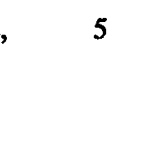 \\
\hline G. chevreuxi & $\mathbf{J}$ & 593 & $\begin{array}{l}\text { Dourduff, } \\
\text { sta. III }\end{array}$ & 8- 3-1974 & up & $\begin{array}{l}\text { upstreamers, } \\
\text { Dourduff, } \\
\text { sta. II } \\
\text { Feb. } 1972\end{array}$ & 4 \\
\hline
\end{tabular}

1) For population $\mathrm{H}, 203$ animals were caught in the drift net while migrating in downstream direction, on 23-2-1974 and 27-2-1974, at the stations II and III; 329 adults were caught with dip nets on 27-2-1974, at station IV.

found migrating in anadromous or in catadromous direction. In $G$. chevreuxi the migratory activity seemed to be correlated more with the occurrence of high tides with high coefficients, than with the reproductive cycle.

All observations summarized above have been concluded after catches with a net designed by Dennert et al. (1969), and no actual observations on migrating animals were available. Tagging experiments (Dennert et al., 1969; Brandse \& Dennert, unpublished) give some information on the actual movements of gammarids, but the numbers of animals recaught are too small for statistical treatment, and therefore are not entirely convincing.

In the present series of experiments, the migratory activity of $G$. zaddachi and $G$. chevreuxi was observed in the laboratory. Simulation of the migration of Gammarus was accomplished with the aid of an apparatus making it possible to observe the animals while a number of environmental factors (temperature, salinity, oxygen supply, current direction and current speed) can be kept constant, or changed at will. In these simulation experiments, the hypothesis mentioned be- fore viz. that there are differences between juveniles and adults with regard to the migratory activity (in anadromous and catadromous direction), was tested. Furthermore it was tried to establish which factor, or combination of factors, is triggering the upstream migration of $G$. zaddachi and $G$. chevreuxi during high tides.

To control whether the migratory activity of G. zaddachi is an adaption to estuarine conditions or not, the activity of $\boldsymbol{G}$. zaddachi originating from stagnant brackish waters was followed in experiments with running fresh water, and with simulated high tide (corresponding with an estuarine environment).

\section{THE EXPERIMENTAL POPULATIONS}

In order to get results comparable with the previous work on the migration of brackish water Gammarus (Dennert et al., 1969; Dennert \& Van Maren, 1974; Girisch et al., 1974) the experimental populations were obtained from the same streams: the rivers Slack (Pas-de-Calais, France) and Dourduff (Finistère-Nord, France). Furthermore G. zaddachi was collected in the North Sea 


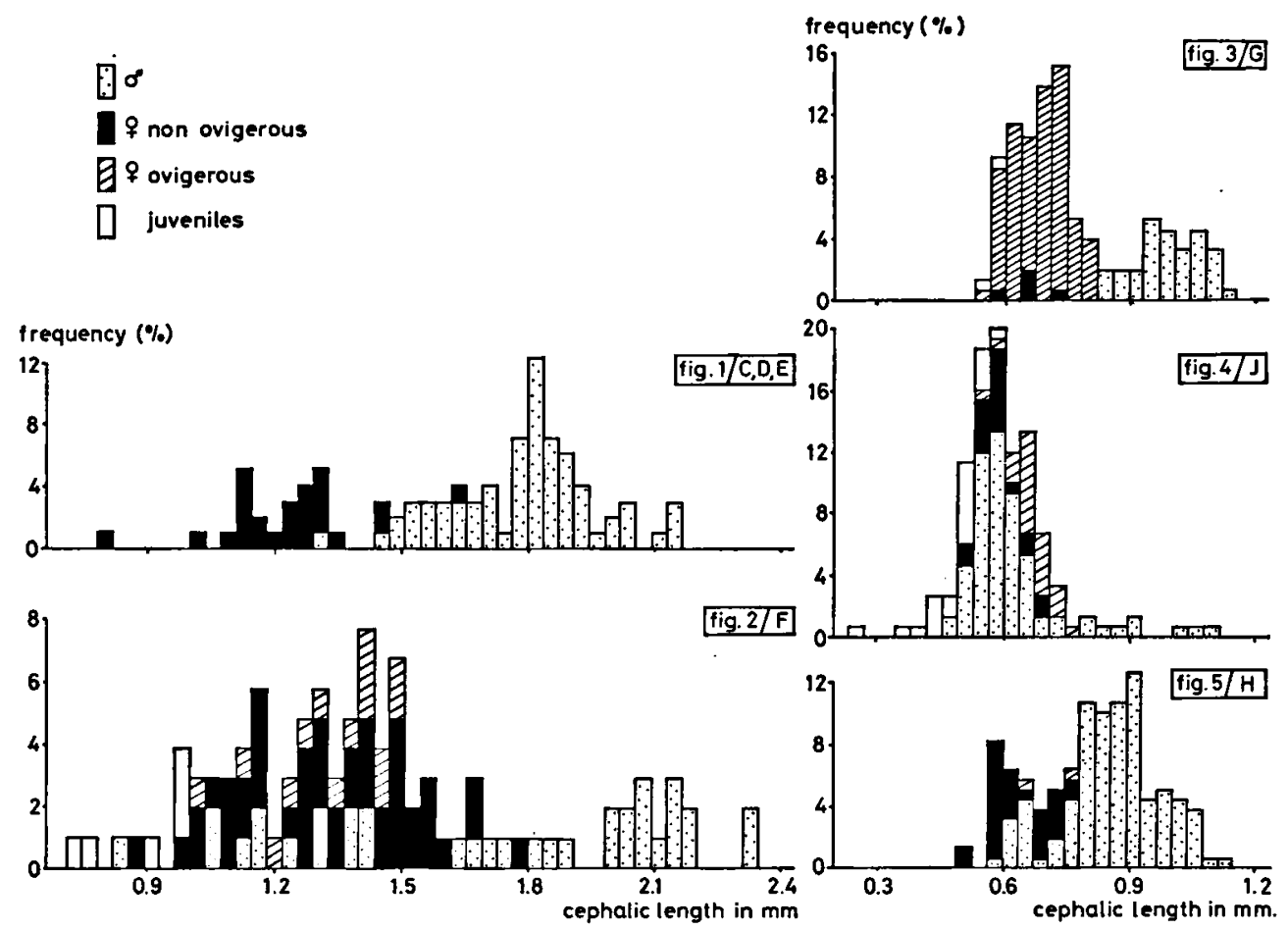

Figs. 1-5. Composition of the experimental populations. Fig. 1, populations C, D, and E (G. zaddachi, Slack). Fig. 2, population F (G. zaddachi, North Sea Canal). Fig. 3, population G (G. chevreuxi, (G. chevreuxi, Dourduff). Fig. 5, population H (G. chevreuxi, Dourduff).

. Fig. 4, population $\mathrm{J}$

Canal (Holland). In table I the origin of each experimental population is given. The same table indicates with which of the samples in the fieldwork of Dennert et al. (1969) and Girisch et al. (1974) the experimental populations can be compared. The composition of the experimental populations is shown in figs. 1-5. For further details on the situation in the rivers Slack and Dourduff we refer to Stock, Nijssen \& Kant, 1966; Dennert et al., 1969 (with map of the river Slack, fig. 1); Dennert \& Van Maren, 1974; Van Maren, 1974; and Gi- risch et al., 1974 (with map of the river Dourduff, fig. 1).

Each batch of freshly caught animals was transported within one day to the laboratory. This was in the case of $G$. zaddachi the Institute of Taxonomic Zoology, Amsterdam, and in the case of G. chevreuxi the Station Biologique, Roscoff (France). During transportation and storage the animals were kept in Slack water or Dourduff water.

Table II. Current velocity in the current chamber immediately above the bottom, and $10 \mathrm{~cm}$ above the bottom. Correlation of the voltage of the motor driving the propeller and the actual current velocity. The downstream direction corresponds with the arrow in fig. 8 , the upstream direction is the opposite. Each value is the mean of five measurements.

Voltage of motor

Mean current velocity in $\mathrm{cm} / \mathrm{sec}$, near the bottom Mean current velocity in $\mathrm{cm} / \mathrm{sec}$, $10 \mathrm{~cm}$ above the bottom

\begin{tabular}{ccccccccccc}
\multicolumn{4}{c}{ Downstream direction } & & & \multicolumn{3}{c}{ Upstream direction } \\
\hline 1.0 & 2.0 & 3.0 & 4.0 & 5.0 & 6.0 & & 2.0 & 3.0 & 4.0 \\
0.7 & 4 & 6 & 7 & 10 & 12 & & 0.9 & 1.5 & 2.8 \\
1.1 & 3 & 4 & 6 & 8 & $\left.7^{2}\right)$ & 1.1 & 2.3 & 2.6 \\
& & & & & & & & & &
\end{tabular}

2) Due to turbulencies the current velocity decreases. 


\section{DESCRIPTION OF THE CURRENT CHAMBER}

All observations were carried out on animals maintained in a current chamber (see figs. 6, 7 and 8). This apparatus is fundamentally an enlargement of the current chamber as used by Vobis (1972), with some modifications. In contradistinction to the chamber of Vobis the animals are allowed to swim around the whole channel. In this respect it is more comparable with the types of current chamber used by Hughes (1969, 1970) and Venema \& Creutzberg (1973). These types have the advantage, that the animals can be observed during a longer period (in our experiments up to three weeks).

The current chamber itself is made of plexiglas, and is housed in an aquarium. The temperature

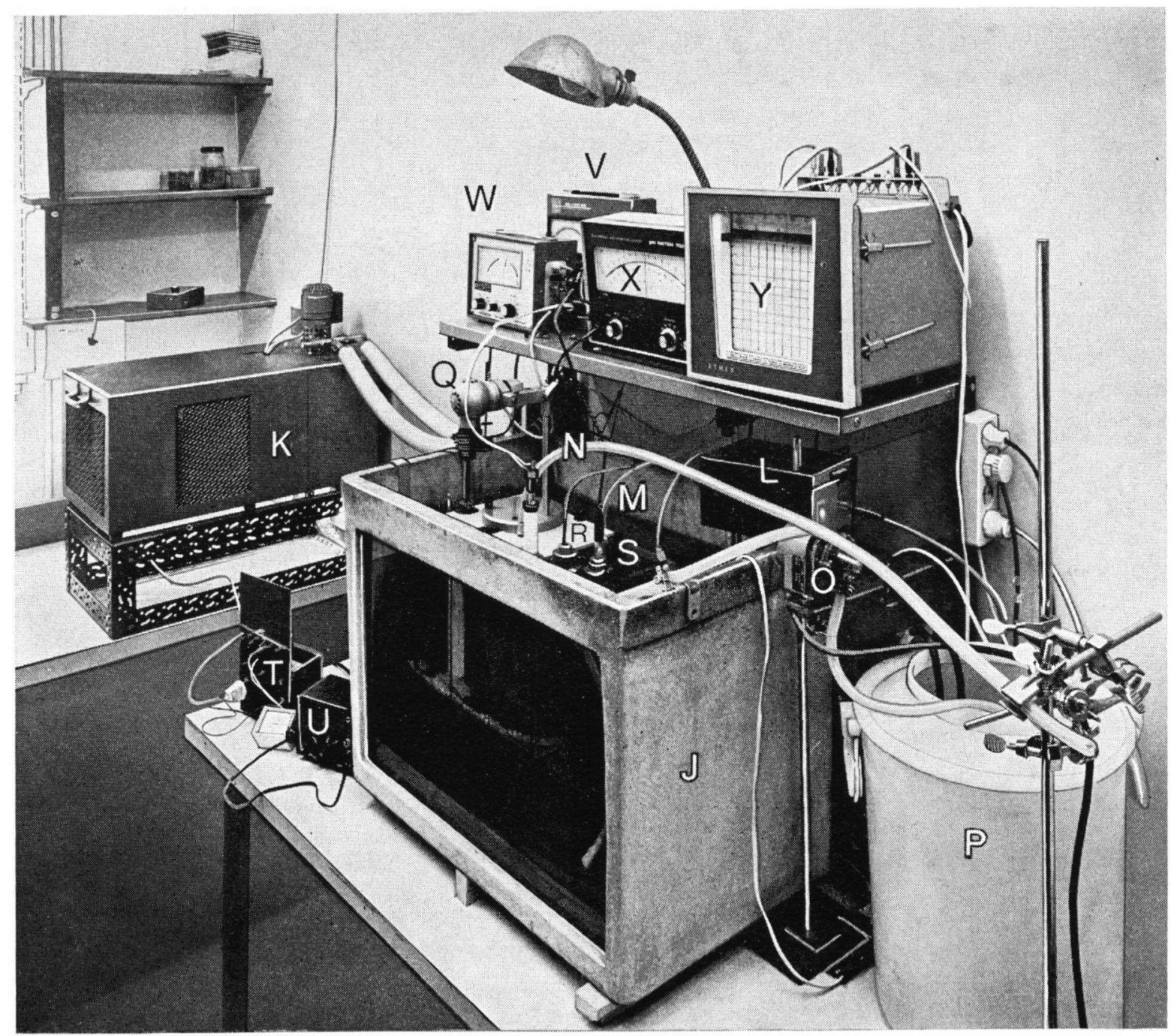

Fig. 6. View of the experimental apparatus. Explanation of the characters:

J aquarium
$\mathbf{K}$ cryostat
$\mathbf{L}$ thermostat
$\mathbf{M}$ inflow tube (outside)
$\mathbf{N}$ overflow tube (outside)
$\mathrm{O}$ pump
$\mathbf{P}$ water container
$\mathbf{Q}$ red lamp

J aquarium

$M$ inflow tube (outside)

$\mathbf{N}$ overflow tube (outside)

$P$ water container

Q red lamp
R untransparent cover (not clearly to be seen)

$S$ cover of the current chamber, with mounted electrodes

$T$ transformer for the motor (in front of it the Voltmeter)

U transformer for the red lamp

$\mathrm{V}$ oxygen meter

W specific conductivity meter

$\mathrm{X}$ pH meter

$\mathbf{Y}$ recorder 


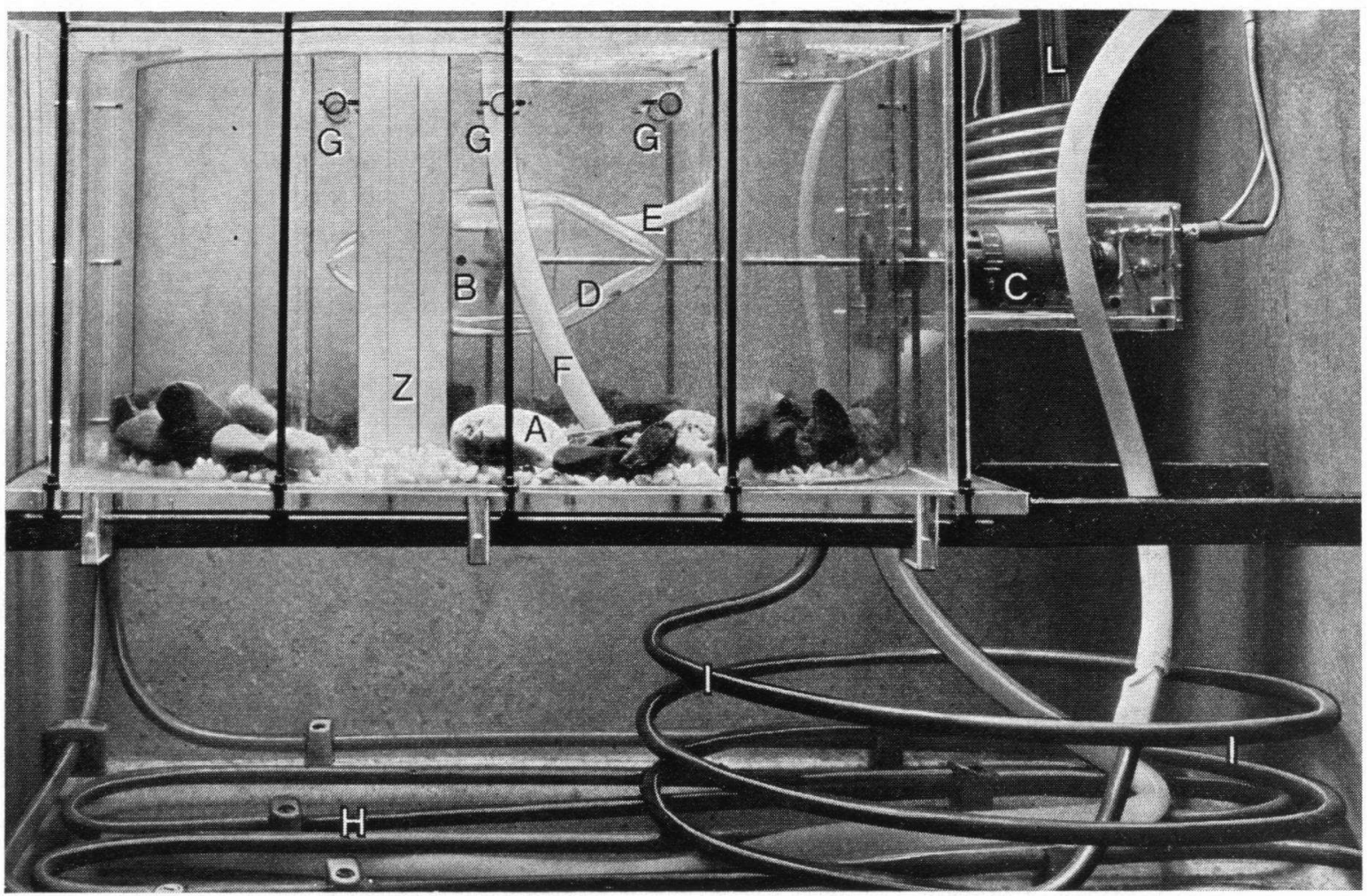

Fig. 7. Front view of the current chamber. Explanation of the characters:
A observation channel
B propeller
C motor
D gauze around the propeller
$\mathrm{E}$ inflow tube (inside)

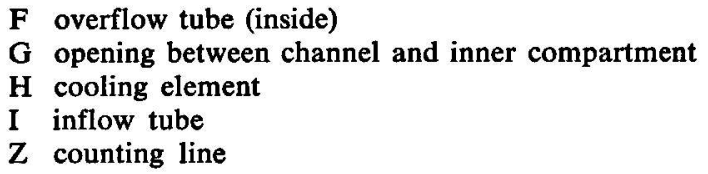

velocities is present. As the velocity meters available were not suited for measuring in narrow channels, stream velocity was simply measured with the help of a suspended object and a stopwatch. The measurements were carried out at various heights in the watercolumn of the chamber in channel A (see fig. 8), and at various voltages of the variable speed motor driving the propeller (fig. 7, C). The measurements are summarized in table II. In the present paper the voltage of the motor is used to indicate the current velocity in the current chamber.

At the simulation of a flood tide, water is pumped in the chamber via an inflow pipe (fig. $6, M$ ) in the cover of the chamber. This inflow is situated just before the propeller. In this way additional turbulence caused by the inflow of water is avoided, and the new water is easily mixed with the old. Care was taken that the inflowing water had the same temperature as the water in the chamber. An overflow (fig. 6, N; 


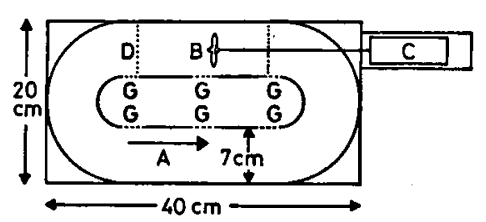

Fig. 8. Diagram of the current chamber. For explanation of the characters see fig. 7. The arrow indicates the current direction during ebb tide.

fig. 7, F) situated in the inner part of the chamber carries off the superfluous water.

Simulation of the sequence flood tide - ebb tide proceeds as follows: In three or four steps the current velocity is reduced to zero, and thereafter a slow current in the opposite direction is established. This procedure takes about $30 \mathrm{~min}-$ utes. Then seawater is pumped into the chamber. In about 20 minutes this results in an increase of the specific conductivity from $700 \mu \mathrm{S}$ to approximately $18,000, \mu \mathrm{S}$. At the same time the temperature is raised $2^{\circ} \mathrm{C}$. After a stable period of about 30 minutes, the current velocity is reduced to zero again, and thereafter a current is established in the same direction and with the same velocity as the initial current. Now fresh water (originating from the same locality as the animals or this water in a

Table III. Changes in salinity, temperature and oxygen content of the water at the bottom of the river Dourduff, station II, at high water spring tide. The salinity is expressed as the specific conductivity of the water. At low tide the chlorinity is $41 \mathrm{mg} / \mathrm{l}$; at high tide a maximum value of $15,000 \mathrm{mg} / 1$ is measured. Coefficient of the high tide is 111. The measurements were taken on 9 March 1974.

Time Specific conductivity in $\mu \mathrm{S}$

Temperature [02] in ppm. in ${ }^{\circ} \mathrm{C}$

\begin{tabular}{lccr}
\hline 16.30 & 310 & 7.3 & 11.6 \\
17.15 & - & 7.3 & 11.6 \\
17.27 & - & 7.4 & 11.4 \\
17.33 & 6,350 & 7.8 & 10.4 \\
17.40 & - & 7.3 & 11.0 \\
17.50 & 35,000 & 8.1 & 10.5 \\
18.00 & - & 8.4 & 10.0 \\
18.10 & - & 8.4 & 9.8 \\
18.15 & 38,000 & - & - \\
18.20 & - & 8.4 & 9.9 \\
18.25 & 37,000 & - & - \\
18.30 & - & 8.4 & 10.2 \\
18.40 & - & 8.4 & 10.0 \\
18.45 & 38,500 & - & - \\
18.50 & - & 8.4 & 10.2 \\
19.00 & - & 8.3 & 10.2 \\
19.05 & 36,500 & - & - \\
19.30 & 1,500 & 8.1 & - \\
\hline
\end{tabular}

mixture with tap water) is pumped into the chamber. Within 15 minutes the salinity drops to a value corresponding with a specific conductivity of $5000 \mu \mathrm{S}$. The total replacement of the water in the apparatus takes over one hour. The procedure as described above is designed in accordance with the situation in the rivers Slack and Dourduff at high tide (see table III and fig. 9; furthermore Dennert et al., 1969: fig. 15, tables V, VI and VII; and Van Maren, 1974: fig. 4).

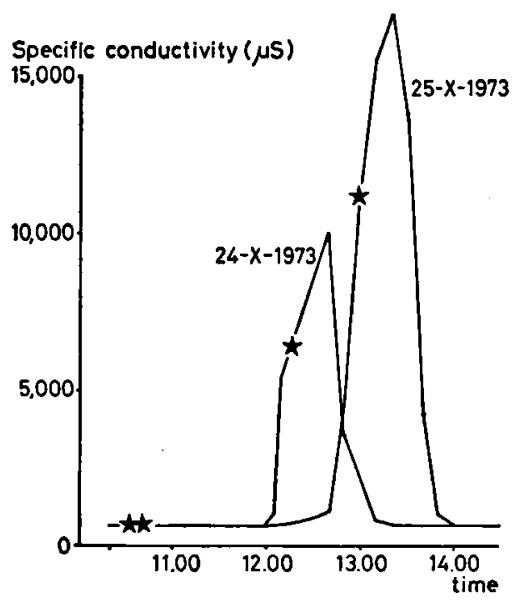

Fig. 9. Salinity (in $\mu \mathrm{S}$ ) during high tide at station I (river Slack). The maximum chlorinity on 24 October 1973 was $3900 \mathrm{mg} / \mathrm{l}$, and the $\mathrm{Ca}++$ content $167 \mathrm{mg} / 1$; on 25 October the chlorinity was $6700 \mathrm{mg} / 1$, and the $\mathrm{Ca}++$ content $212 \mathrm{mg} / 1$. An asterisk indicates a moment with a current velocity of zero.

As $\mathrm{pH}$ and oxygen concentration show only minor fluotuations in the rivers Slack and Dourduff, no special attention has been paid to these two environmental factors. At ebb tide simulations the $\mathrm{pH}$ was kept at $7.4 \pm 0.1$, and at flood tide simulations at $7.8 \pm 0.1$. These are the same values as found in the rivers Slack and Dourduff. ${ }^{3}$ ) In all experiments the water used was saturated with oxygen, like it was under natural conditions in the Dourduff (see table III).

The actual observations on migrating animals consisted of the counting of the animals that moved across a black line on a white background (fig. $7, \mathrm{Z}$ ). In some experiments this line was divided in four equal parts; the uppermost quarter was labelled $\mathrm{D}$, and the lowest quarter was labelled A.

3) It should be noted that owing to the inaccuracy of pH paper, the $\mathrm{pH}$ values published by van Maren (1974) are incorrect, and in general $2 \mathrm{pH}$ unities too low. 
In fig. 8, where the current chamber is shown in a diagram, the arrow indicates the direction of the current during ebb tide simulation (downstream direction). So in our experiments "downstream migrating animals" are moving in this direction, irrespective of the actual current direction. Hence during flood tide simulation the downstream migrating animals are moving against the current. The opposite holds true for the "upstream migrating animals". During ebb tide simulation these are moving against the current, and during flood tide simulation they go with the stream.

At night the current chamber was either completely dark, or illuminated through a slit by a red lamp $(\lambda=630 \mathrm{~nm})$. At the counting line the intensity of the red light was just bright enough to permit a count of animals moving across this line. At daytime, the daylight could penetrate through a window but moreover the chamber was illuminated by a 100 Watt lamp.

During the experiments the animals were fed with the weed Stellaria media Vill. In section IV. 3 the problems concerned with the influence of the food supply on the migratory activity are further discussed.

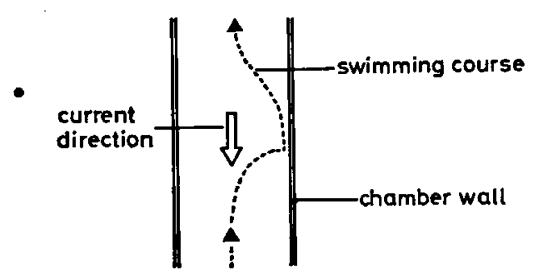

Fig. 10. Track of large animals swimming against the current (seen from above).

Dependent from the experiment, several types of substratum have been used. In pilot experiments, for each species a substratum was established that could be used best in the experiments. The pilot experiments have shown, that when the substratum offers too much shelter, the migratory activity at a given population density decreases. On the other hand, when the substratum offers too little shelter, the animals have no opportunity to hide at daytime. This results in a considerable stress on the animals which is not conducive to the experiment. In our experiments we started with a search for an equilibrium between the type of substratum and the number of animals in the chamber, so that a clear day/night periodicity in the activity of the Gammarus species concerned was detectable. Since $G$. zaddachi is larger than $G$. chevreuxi, the number of animals to be used was lower in the case of G. zaddachi. For the same reason, gravel (particle size 2-16 $\mathrm{mm}$ ) was used in the experiments with $G$. chevreuxi, and a mixture of gravel and pebbles (particle size 4-64 $\mathrm{mm}$ ) in the experiments with $G$. zaddachi (terminology according to Cummins, 1962).

\section{BEHAVIOUR OF GAMMARUS IN RUNNING FRESH WATER}

\section{1. Upstream and downstream migrants}

In section III it is pointed out, which current direction in the current chamber is labelled the downstream direction. Except for the periods in which a flood tide is simulated, the current direction was kept in this way. In all experiments, both downstream and upstream movements were recorded. The nature of these movements, however, is not the same.

Animals migrating in upstream direction are mostly large animals, actively swimming against the current (positive rheotropism).

Active migrants in downstream direction form only a part of the number of animals that move in the chamber in downstream direction. Most of the downstream moving animals are drifters: animals that cease swimming against the current for a while, and are carried away passively by the current. Furthermore drifters are recruited from animals crawling on the substratum. When such animals loose contact with the substratum, they are carried away by the current. The latter two types of downstreamers often pass the observation line on their back, not swimming at all.

When a Gammarus is not able any more to swim against the current, and enough space is available, the animal makes a $180^{\circ}$ turn and is carried away in downstream direction. Now near the walls of the chamber the current speed is often lower than in the middle part of the channel (see section III). An animal, acting as described above, may continue its course in upstream direction in such a zone of low current velocity instead of been carried away in downstream direction (see fig. 10). In nature the same may occur along river banks, but the streambed is much wider than the channel in the current chamber. Therefore such zones of low current velocity will be less available for animals in a river than in the relatively narrow current 
chamber. For this reason the ratio (actively migrating upstreamers)/(downstreamers) is probably much higher in our experiments than in nature. The artefact mentioned here counts more for the larger species (G. zaddachi), than for the smaller (G. chevreuxi).

Since under constant conditions, the ratio (actively migrating upstreamers)/(downstreamers) is rather constant within one species, this ratio is used as a reference in our experiments. In this light it is clear, that the absolute number of migrants recorded in an experiment has less significance, but the difference in activity within one experiment (occurrence of an activity peak) must be taken into consideration.

In fresh water (specific conductivity 450 to 700 $\mu \mathrm{S})$, at moderate temperatures $\left(7^{\circ}-8^{\circ} \mathrm{C}\right)$ and constant current speed (equivalent to $3 \mathrm{~V}$ ), in $G$. chevreuxi the number of downstream migrating animals is equal to, or somewhat higher than the number of actively migrating upstreamers. In G. zaddachi originating from the river Slack the number of downstreamers is always higher than the number of actively migrating upstreamers. $G$. zaddachi from the North Sea Canal shows a strong positive rheotropism. In the experiments carried out at a specific conductivity of $2000 \mu \mathrm{S}$, the number of actively migrating animals is higher than the number of passive downdrifters. At a specific conductivity of the medium of $600 \mu \mathrm{S}$, the number of downdrifters is somewhat larger than the number of animals actively swimming against the current.

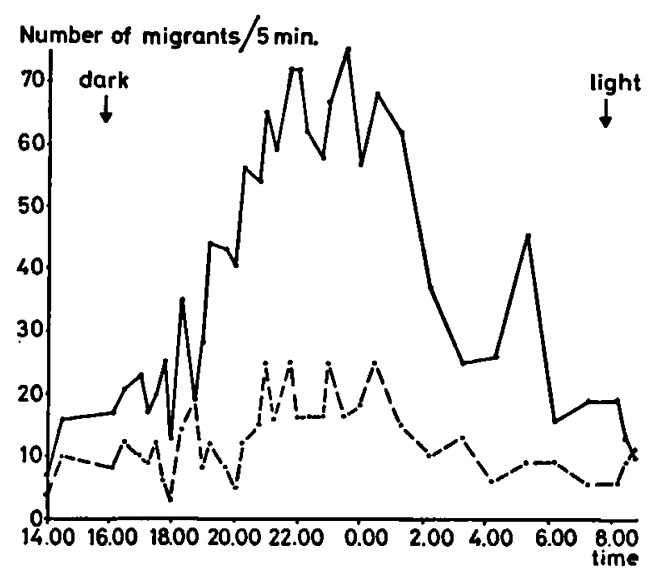

Fig. 11. Diurnal periodicity of $G$. zaddachi in the current chamber (14/15 january 1974 , population $C)$. Uninterrupted line = "downstream" migrants, dashed line = "upstream" migrants. Experimental conditions: current velocity $2.8 \mathrm{~V}$, downstream direction; specific conductivity $550 \mu \mathrm{S}$; temperature $8^{\circ} \mathrm{C}$.

\section{2. Diurnal periodicity}

The day/night activity pattern as described by Dennert et al. (1969) and Girisch et al. (1974) for natural populations of $G$. zaddachi and $G$. chevreuxi, respectively, is also recorded in the current chamber. In fig. 11 the diurnal periodicity of $G$. zaddachi as recorded in the chamber is shown. In fig. 12 the same is shown for $G$. chevreuxi. These two figures are in complete agreement with Dennert et al. (1969: figs. 12-14) and Girisch et al. (1974). Note that the second activity peak in the case of $G$. chevreuxi (fig. 12) is caused by the simulation of a flood tide in the current chamber.

Our observations on the diurnal rhythm of $G$. zaddachi originating from the North Sea Canal are more scattered than the observations on the animals from the river Slack, but table IV, in which these observations are summarized, shows the same tendencies as in the case of $G$. zaddachi originating from the river Slack.

Table IV. Diurnal periodicity of G. zaddachi originating from the North Sea Canal. Observations on 24 and 25 April 1974. The temperature in the current chamber, the specific conductivity, and the current velocity (downstream direction) were kept constant at $10.5^{\circ} \mathrm{C}, 2100 \mu \mathrm{S}$, and $1.5 \mathrm{~V}$, respectively.

\begin{tabular}{lll} 
Time & $\begin{array}{l}\text { Number of } \\
\text { downstream } \\
\text { migrants/min. }\end{array}$ & $\begin{array}{l}\text { Number of } \\
\text { upstream } \\
\text { migrants } / \mathrm{min} .\end{array}$ \\
\hline
\end{tabular}

\begin{tabular}{rrr}
12.00 & 1 & 2 \\
14.30 & 1 & 7 \\
16.20 & 0 & 8 \\
20.00 & 4 & 23 \\
20.15 & 6 & 11 \\
20.30 & 5 & 11 \\
21.00 & 5 & 14 \\
21.30 & 3 & 7 \\
21.45 & 3 & 9 \\
22.15 & 3 & 9 \\
23.00 & 6 & 10 \\
0.00 & 5 & 8 \\
14.00 & 4 & 4 \\
16.00 & 6 & 4 \\
\hline
\end{tabular}

\section{3. Influence of food supply}

Hughes (1970) reported that the migration of G. pulex stopped nearly completely when food was available in his current chamber. The same holds true in our experiments. In fig. 13 the number of migrants during the $21.00 \mathrm{~h}$ activity peak of 20 successive days is shown. The experimental animal was $G$. zaddachi. With food in the 

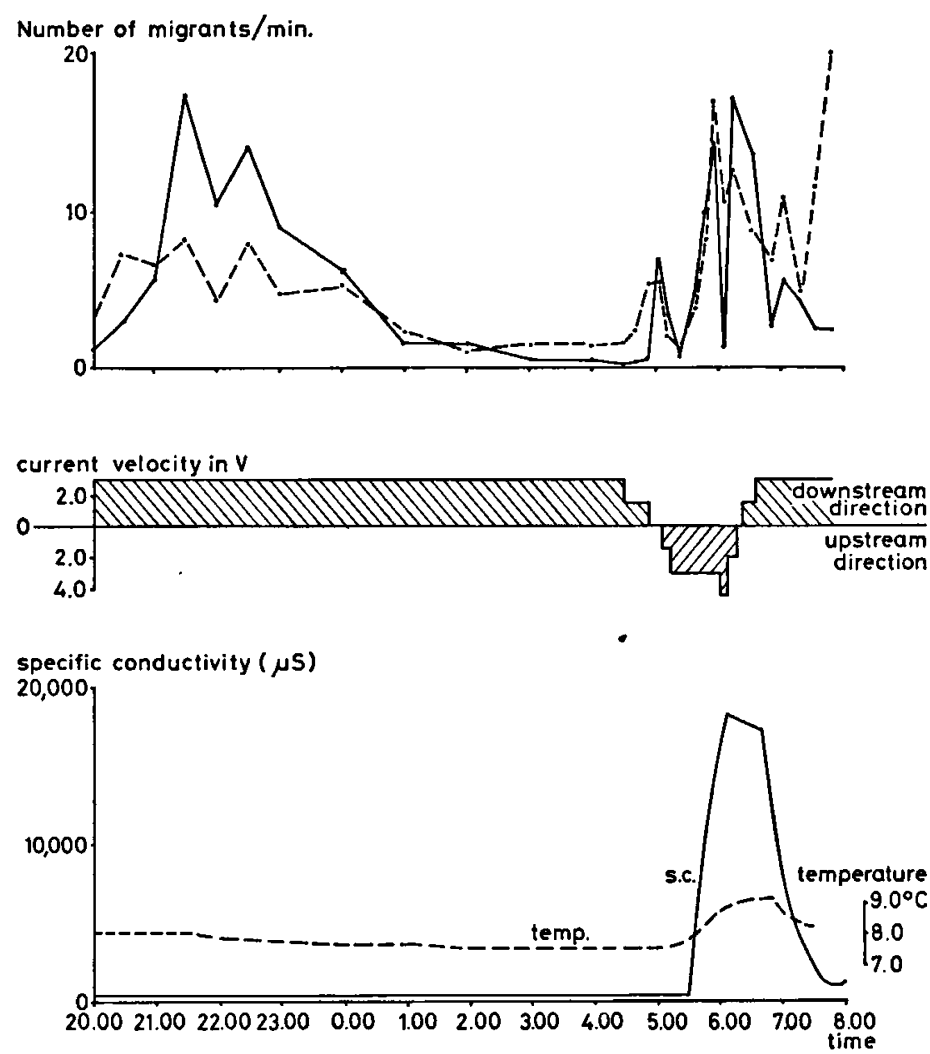

Fig. 12. Diurnal periodicity of $G$. chevreuxi in the current chamber, in combination with the simulation of a complete tidal cycle (25/26 February 1974, population G). Uninterrupted line = "downstream" migrants, dashed line = "upstream" migrants. Indicated are the changes in current speed and current direction, and the changes in specific conductivity and temperature of the medium. For explanation see section III of the text.

chamber, the activity is very low, removal of the food results within one hour in an increase of the activity to normal values.

Hence in our experiments no food was furnished in the experiments lasting one or two days; in the prolonged experiments food was supplied after a series of observations at night, while the remnants of the food were removed the following day.

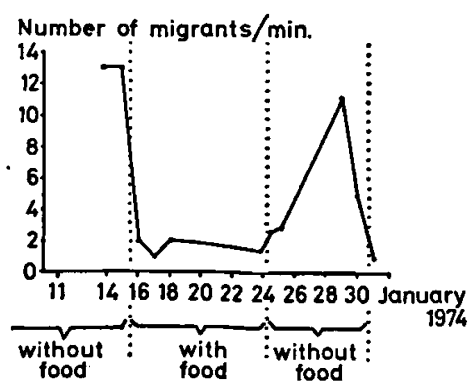

Fig. 13. Influence of food supply on the downstream migration of G. zaddachi (population C). Experimental conditions: current velocity $3 \mathrm{~V}$, downstream direction; specific conductivity $700 \mu \mathrm{S}$; temperature $8^{\circ} \mathrm{C}$.

\section{4. Influence of a rise of the temperature}

A rise of the temperature, lasting several days, has a considerable effect on the migratory activity of $G$. zaddachi and G. chevreuxi. Fig. 14 displays the effect of a temperature rise from $8^{\circ} \mathrm{C}$ to $14^{\circ}$ $\mathrm{C}$ on the activity of $G$. zaddachi. In this figure the mean values of 3 counts taken from $20.45 \mathrm{~h}$ to $21.15 \mathrm{~h}$ on six successive days are given. Only downstream migrating animals were taken into consideration. At $14^{\circ} \mathrm{C}$ the activity is the threefold of that at $8^{\circ} \mathrm{C}$.

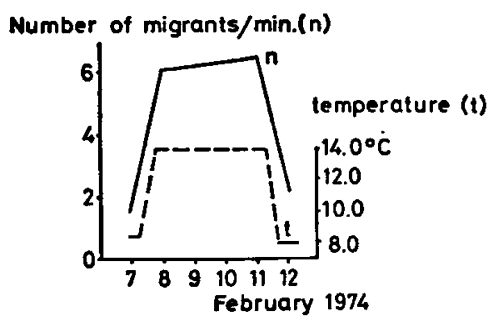

Fig. 14. Influence of the temperature on the downstream migration of $G$. zaddachi (population E). Experimental conditions: current velocity $3.5 \mathrm{~V}$, downstream direction; specific conductivity $700 \mu \mathrm{S}$. 
In $G$. chevreuxi a similar effect of a long lasting rise in the temperature was recorded. When the temperature was brought from $8^{\circ} \mathrm{C}$ to $12^{\circ} \mathrm{C}$ the number of downstream migrating animals was doubled. The number of upstream migrating animals increased in such a way, that counting became impossible.

The influence of a quick rise of the temperature during flood tide is investigated in section V. 4.

\section{THE BEHAVIOUR OF GAMMARUS AT A TIDAL CYCLE SIMULATION}

\section{1. Introduction}

In the following experiments, in which a tidal cycle is simulated either completely or only partially, it was tried to elucidate the questions (1) whether there is any difference in the migratory activity between adult and juvenile gammarids, and (2) which factor, or combination of factors, triggers the migratory activity of $G$. zaddachi and G. chevreuxi 4). $^{\text {) }}$

For a better understanding of the influence of such parameters as current direction and current speed, salinity, temperature, and population density on the migration of both species, these factors are first treated separately, while in section V. 5 a synthesis of the results of the experiments is given.

\section{2. Influence of current direction and current velocity}

The influence of current direction and current velocity was demonstrated for $G$. chevreuxi in experiments with populations $\mathrm{G}, \mathrm{H}$, and J. From these experiments three examples are given in the figs. 15,16 and 17.

In fig. 15 the influence of current speed and current direction is shown in an experiment with population $\mathbf{J}$ (originally upstream migrants from the Dourduff), in which only these two factors were varied and the other two factors investigated, viz. salinity and temperature, were kept constant at a specific conductivity of $460 \mu \mathrm{S}$, and a tem-

4) In the course of the experiments we gathered many data concerning the trigger for the migration at high tide. However, we have not been able to study separately all parameters concerned. Therefore, concerning the second aim of our study, viz. to find the trigger for the migration at high tide, the present paper has to be considered as a progress report. The work will be continued in our laboratory.
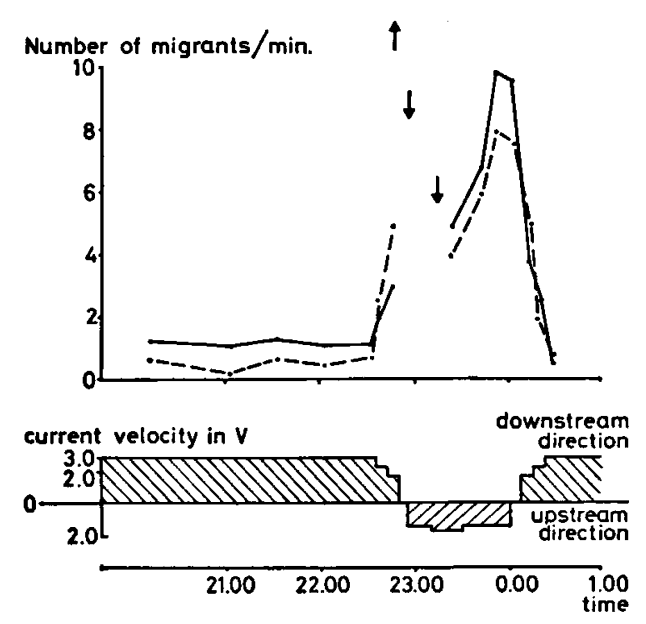

Fig. 15. Influence of current direction and current velocity on the migratory activity of $G$. chevreuxi $(15 / 16$ March 1974, population J). An arrow pointing up indicates the start or the increase of a high activity, the animals swimming almost exclusively up and down in vertical direction. Counting of the upstream and downstream migrants is nearly impossible. An arrow pointing down indicates a decrease or the stop of the up and down activity. Uninterrupted line = "downstream" migrants, dashed line = "upstream" migrants.

perature of $7.7^{\circ} \mathrm{C}$, respectively. Clearly $\mathrm{i} t$ is shown, that when the current velocity decreases, the activity of $G$. chevreuxi increases. At high current speed (corresponding with $3 \mathrm{~V}$ ) the activity of the animals is rather low.

Practically the same as is stated above for the experiment with population $\mathbf{J}$, can be said for experiments with population $\mathrm{H}$ (originally downstream migrants), and population $\mathrm{G}$ (originally upstream migrants). In these experiments (see figs. 16 and 17) not only current speed and current velocity were varied, but also salinity and temperature, thus simulating a complete tidal cycle.

Note, that in both experiments at a low current velocity the animals that actually swim against the current are always more numerous than the animals swimming with the current. When the current direction is reversed in "upstream" sense, the downstreamers are more active, while at a current in downstream direction (see section IV. 1) the upstreamers are more active. In the figs. 24 and 29 more information on the influence of current speed and current direction on the activity of $G$. chevreuxi can be found. These figures will be discussed in the sections V. 3 and V. 4.

G. zaddachi, originating from the river Slack, shows likewise an increase in activity at decreasing current velocity; this was demonstrated in the 

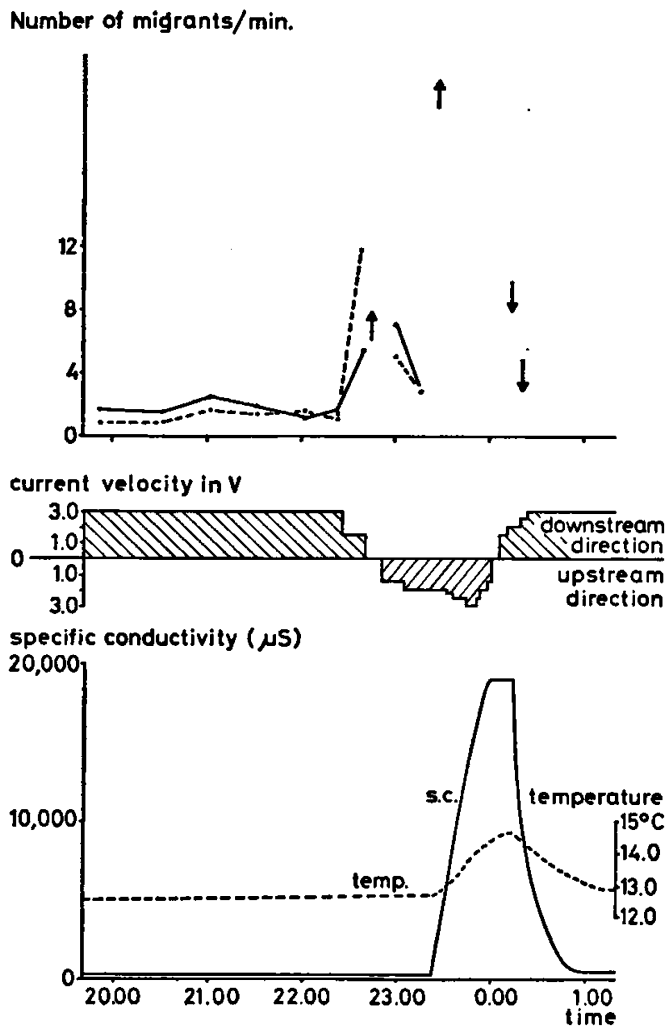

Fig. 16. Influence of a tidal cycle on the migratory activity of $G$. chevreuxi (6/7 March 1974 , population G). For explanation see fig. 15 , and the sections V.2 and V.3 of the text.

populations A, B and C. From these experiments two examples are given in the figs. 18 and 19.

Fig. 18 illustrates an experiment with originally upstream migrants (population A). In this experiment a complete tidal cycle was simulated. Relatively high activity was recorded during periods with low current velocity.

Originally downstream migrants (population C) were used in other experiments. Fig. 19 displays the results of one of these experiments. Here one finds the same tendencies as in experiments with population $\mathbf{A}$, viz. a relatively high activity during periods with low current velocities.

$G$. zaddachi originating from the stagnant water of the North Sea Canal (population F) gives more or less the same results as $\boldsymbol{G}$. zaddachi originating from the river Slack. An example of these results is given in the figs. 20 an 21 . Under practically all circumstances a greater number of animals is found moving against the current, than along with the current.

When during the simulation of a tidal cycle the
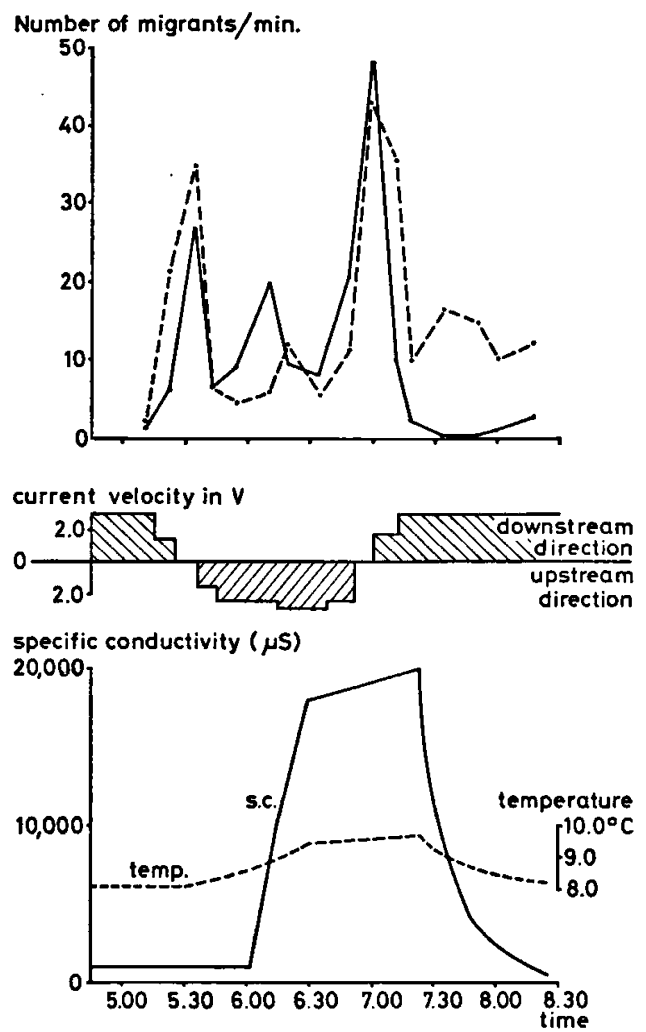

Fig. 17. Influence of a tidal cycle on the migratory activity of $G$. chevreuxi (27/28 February 1974 , population H). For explanation see fig. 15, and the sections V.2 and V.3 of the text.

current velocity in upstream direction becomes too high, the initial increase of the activity caused by the reversal of the current direction ceases. This is shown for G. zaddachi in figs. 18 and 19, and for $G$. chevreuxi in fig. 12. In these experiments the current velocity in upstream direction during flood tide simulation was almost as fast as it was in downstream direction during ebb tide simulation (see also table II). Under these circumstances the animals do not swim anymore against the current, they merely crawl over the substratum against the current.

\section{3. Influence of salinity changes}

A second factor of major importance provoking migratory activity of $G$. zaddachi and $G$. chevreuxi is a change in the salinity of the medium. Our experiments have clearly shown, that during flood tide simulation on top of the influence of the current velocity and current direction a rise in the salt content of the water has a strong effect on the 

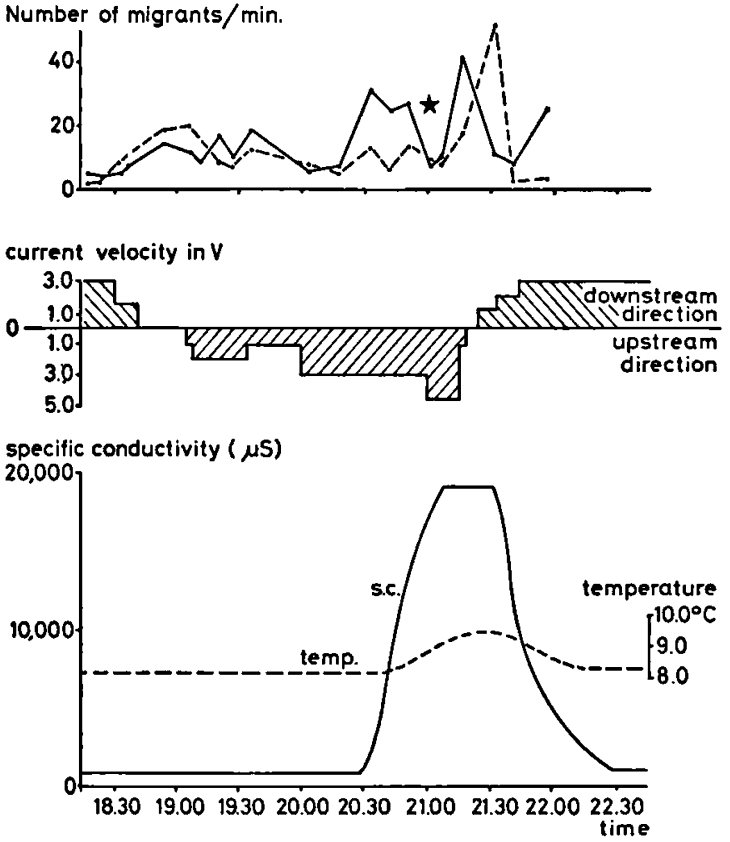

Fig. 18. Influence of a tidal cycle on the migratory activity of $G$. zaddachi (18/19 December 1973, population A). The asterisk indicates a drop in the activity caused by too high a current velocity in upstream direction. For explanation see fig. 15, and the sections V.2 and V.3 of the text.

migratory activity of $G$. zaddachi and $G$. chevreuxi. This is demonstrated in the figs. 12 , and 16 to 21 .

Before discussing these illustrations with regard to this point, some results will be given of experiments with populations $\mathbf{G}$ and $\mathbf{J}$ (G. chevreuxi), and $\mathrm{D}$ and $\mathrm{F}$ ( $G$. zaddachi), experiments in which the effect of salinity changes without simultaneous changes in current velocity are studied.

In experiments with populations $G$ (fig. 22) and $J$ (fig. 23) the effect is investigated of a salinity and temperature change similar to the changes found in nature during a tidal cycle. These illustrations show, that independent of the time of night, the response of $G$. chevreuxi on the change in salinity and temperature is nearly the same as a response of this species on the simulation of a complete tidal cycle (fig. 12). Figs. 16 and 17, mentioned above, show more or less the same results, with regard to the influence of salinity changes on the activity of $G$. chevreuxi, as the figs. 22 and 23 . The experiments on which figs. 16 and 17 are based have been carried out with originally downstream migrants, and originally upstream migrants, respectively.
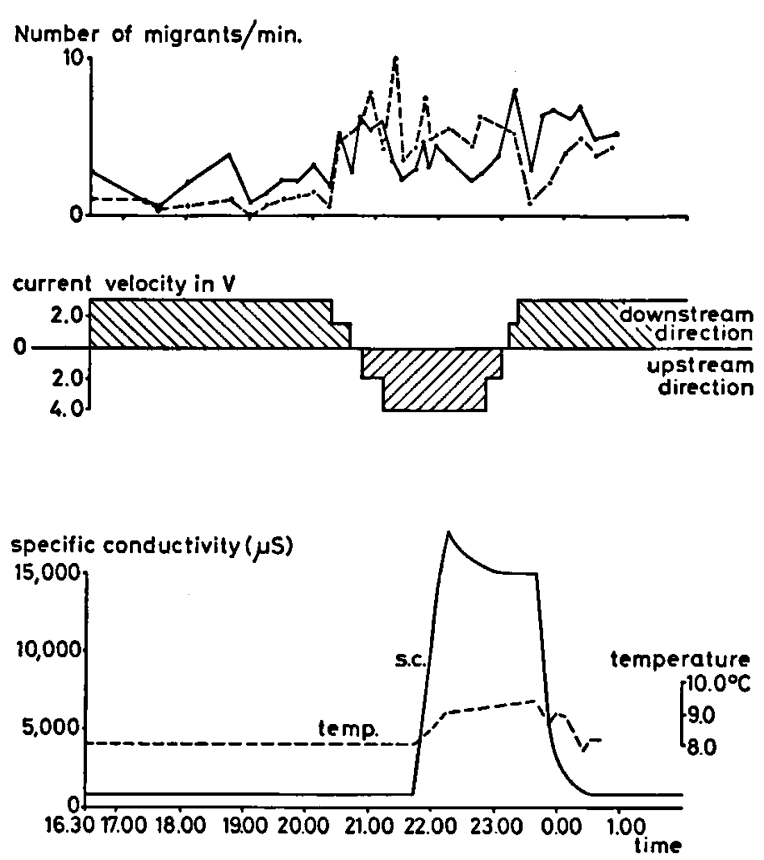

Fig. 19. Influence of a tidal cycle on the migratory activity of $G$. zaddachi (25/26 January 1974, population C). For explanation see fig. 15, and the sections V.2 and V.3 of the text.

Another example of the positive influence of a rise in salinity is found in an experiment with population $\mathrm{J}$ which lasted 7 experimental days. The results of one observation night are given in fig. 24. Here also activity could be induced at a time at night, when normally the animals are practically inactive.

So in $\boldsymbol{G}$. chevreuxi an increase of the salinity from freshwater values to values falling in the mixohaline category causes an increase in activity. When during an experiment the activity induced by the reversal of the current direction disappears due to too high a current velocity, a rise in the salinity of the medium results in a second activity peak (see fig. 12).

In $G$. zaddachi a rise in the salinity of the medium not always results in an activity peak. The effect of a change in salinity only, the other factors being kept constant, on the activity of $G$. zaddachi is shown in fig. 25. This figure, based on an experiment with population D (see table I), shows that after an initial increase of the activity, especially of the animals actually moving with the current, the activity drops and becomes negligible. More or less the same phenomenon, although not 

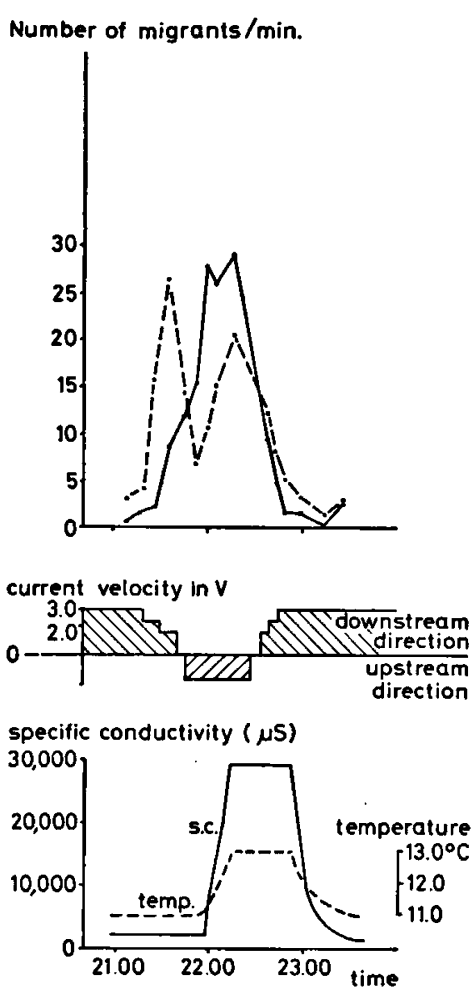

Fig. 20. Influence of a tidal cycle on the migratory activity of $G$. zaddachi (1 May 1974, population F). For explanation see fig. 15, and the sections V.2 and V.3 of the text.

always clear, can be seen in the experiments with G. zaddachi in which also current speed and temperature are changed. These are the experiments with population B (fig. 26), and the experiments mentioned before, viz. with population A (fig. 18) and $C$ (fig. 19). One must keep in mind, that in the experiments with populations $A, B$ and $C$ the current velocity in upstream direction was rather high (corresponding with 4 or $5 \mathrm{~V}$ ) during the simulation of a tidal cycle, and that probably this current velocity has a decreasing effect on the activity of $G$. zaddachi. The asterisk in fig. 18 indicates such a situation.

G. zaddachi originating from the North Sea Canal reacts in the same way as the animals originating from the river Slack do when the salinity of the medium is changed (see figs. 20 and 27).

Summarizing one may say that apart from a change in the current velocity, a change in the salinity of the medium may cause a considerable
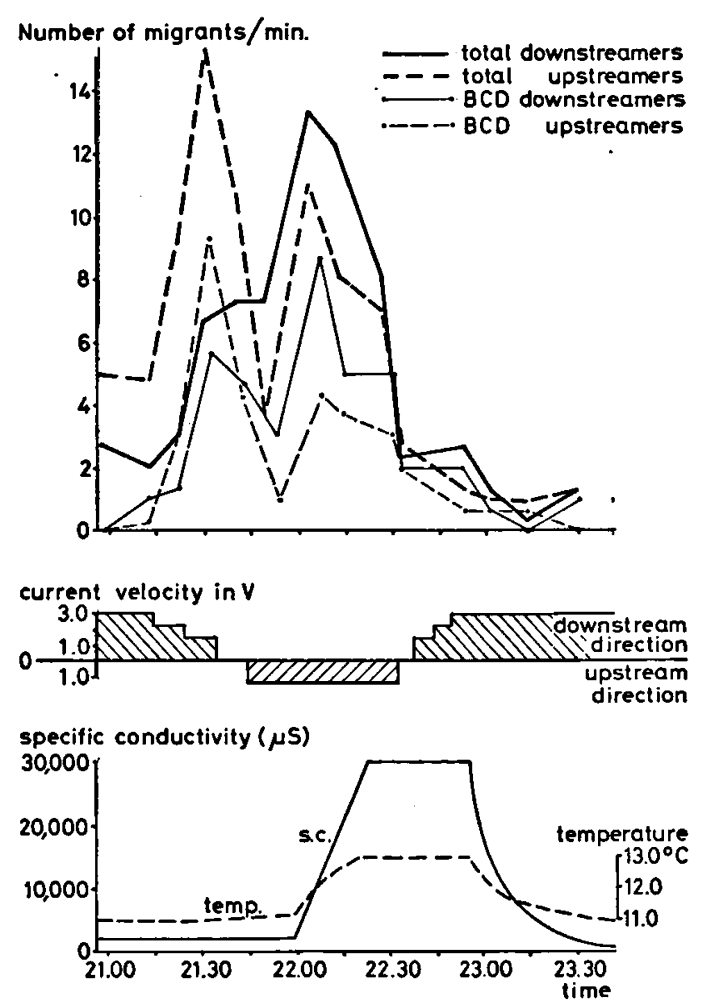

Fig. 21. Influence of a tidal cycle on the migratory activity of $G$. zaddachi (2/3 May 1974, population F). In this experiment the counting line was divided in four equal parts (see section III). The activity in the top three fourth of the chamber (subdivisions B, C and D), and the total act'vity (subdivisions A-D) are indicated separately. For further explanation see fig. 15, and the sections V.2 and V.3 of the text.

increase of the migratory activity of both $G$. zaddachi and $G$. chevreuxi.

In $G$. chevreuxi the distinction between originally upstream migrants and originally downstream migrants is not very clear. In the experiments with $G$. chevreuxi, regardless of the origin of the experimental population, and regardless of the current direction, the animals actually swimming against the current mostly outnumber the animals swimming along with the current. On the other hand, in G. zaddachi the originally downstream migrants have a more pronounced reaction on the increase of the salinity of the medium than the originally upstream migrants.

\section{4. Influence of a quick rise in temperature}

In the rivers Dourduff and Slack, the water temperature changes during a flood tide. In winter the sea water is warmer than the river water, so 

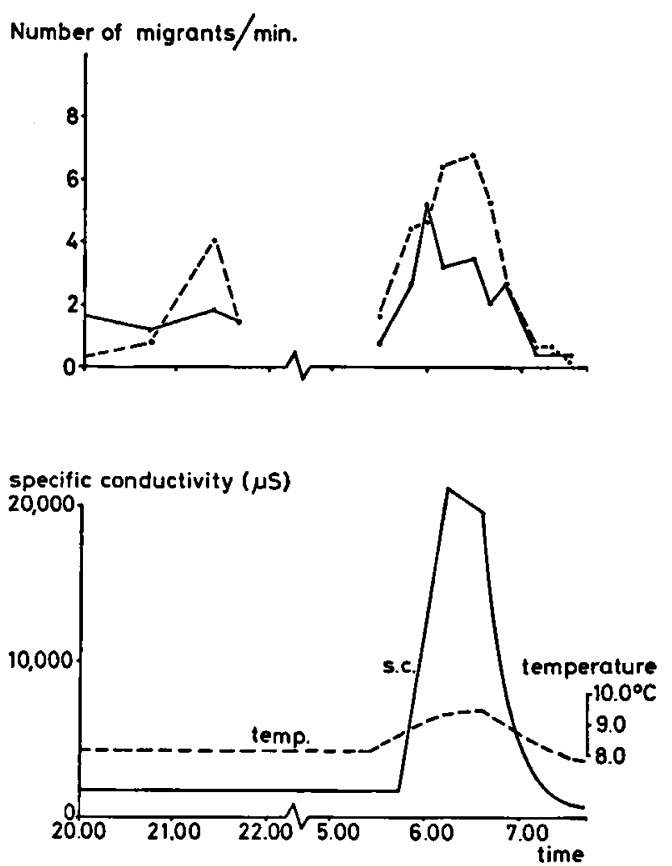

Fig. 22. Influence of a rise in the salinity and temperature of the medium on the migratory activity of $G$. chevreuxi (1/2 March 1974, population G). The current velocity was kept constant at $4 \mathrm{~V}$ in downstream direction. For explanation see fig. 15, and section V.3 of the text.
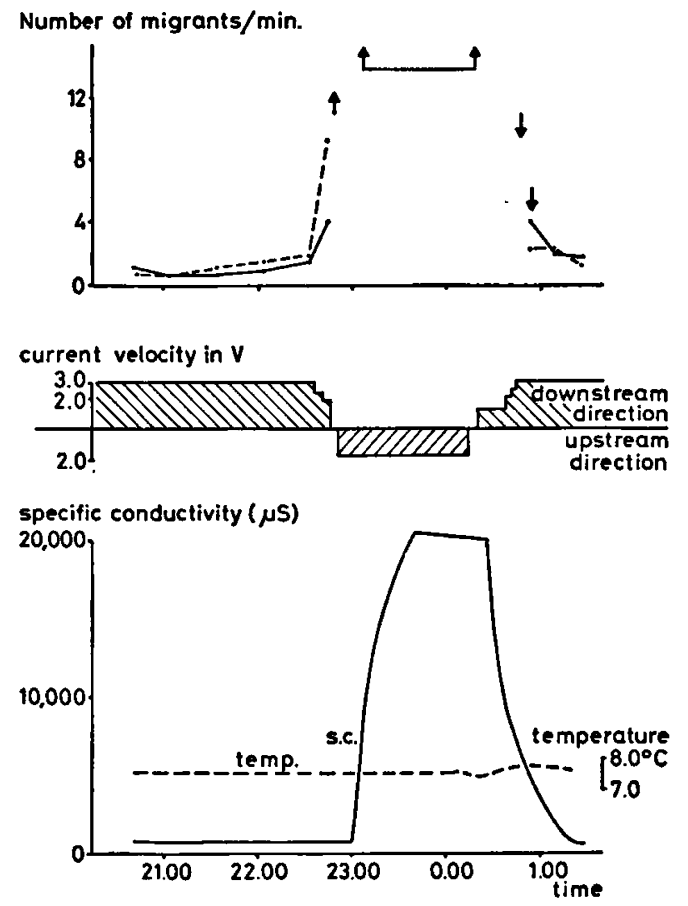

Fig. 24. Influence of a tidal cycle without a rise in temperature on the migratory activity of $G$. chevreuxi (17/ 18 March 1974, population J). For explanation see fig. 15 , and section V.3 of the text.
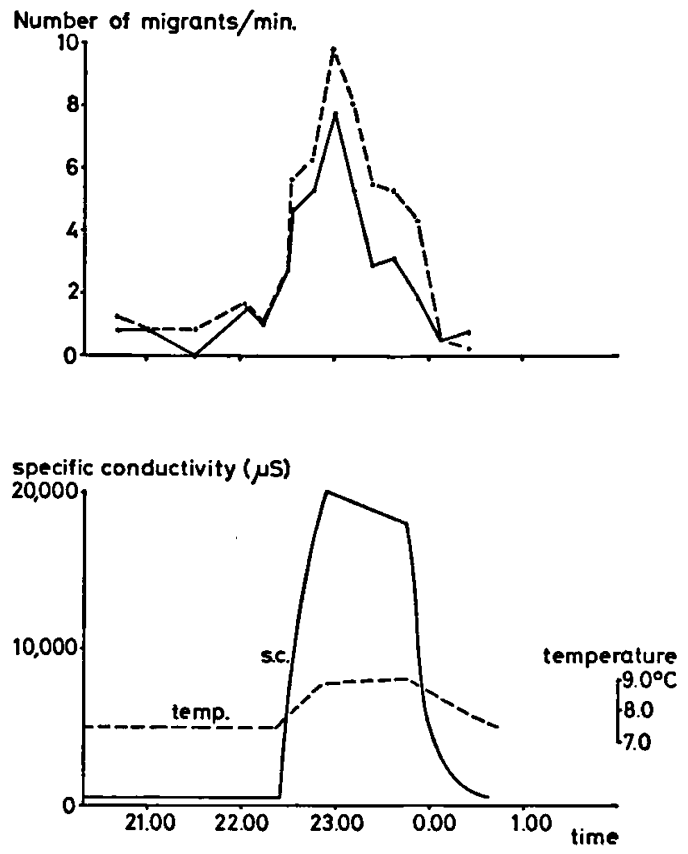

Fig. 23. Influence of a rise in the salinity and temperature of the medium on the migratory activity of $G$. chevreuxi (16/17 March 1974, population J). The current velocity was kept constant at $3 \mathrm{~V}$ in downstream direction. For explanation see fig. 15, and section V.3 of the text.
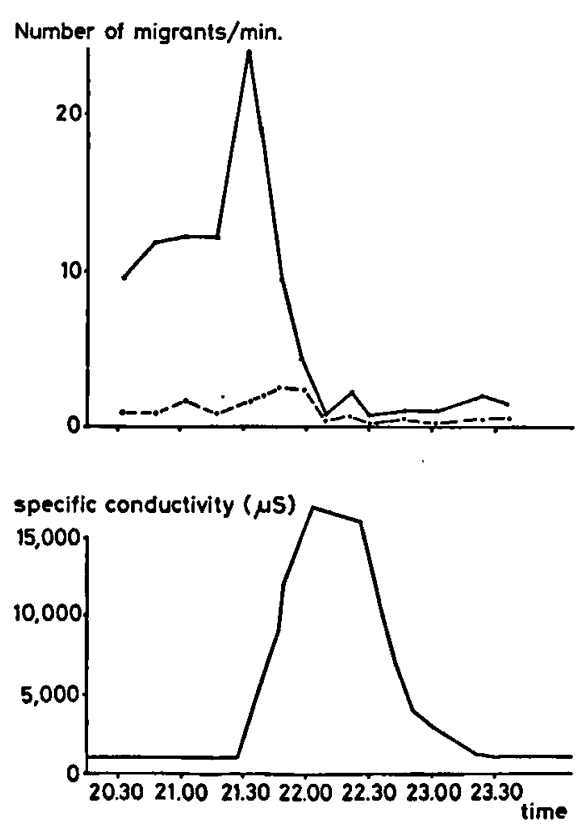

Fig. 25. Influence of a change in the salinity of the medium on the migratory activity of $G$. zaddachi $(5 / 6$ February 1974, population D). Temperature and current velocity were kept constant at $8.1^{\circ} \mathrm{C}$ and $3 \mathrm{~V}$ in downstream direction, respectively. For further explanation see fig. 15, and section V.3 of the text. 

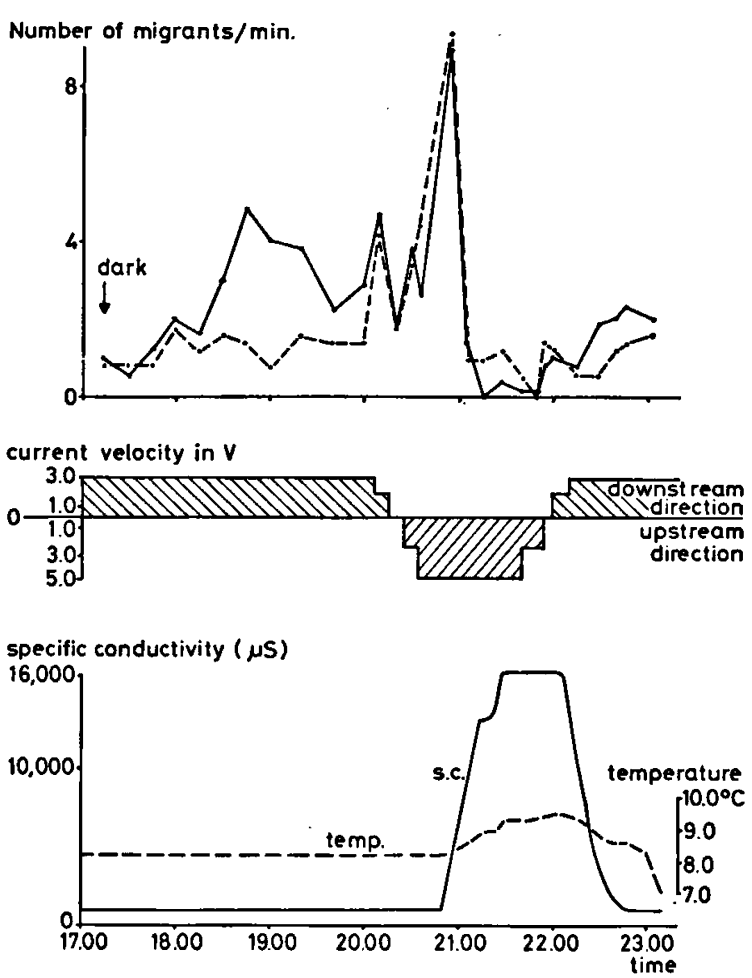

Fig. 26. Influence of a tidal cycle on the migratory activity of $G$. zaddachi (8/9 January 1974, population B). For explanation see fig. 15 , and section V.3 of the text.
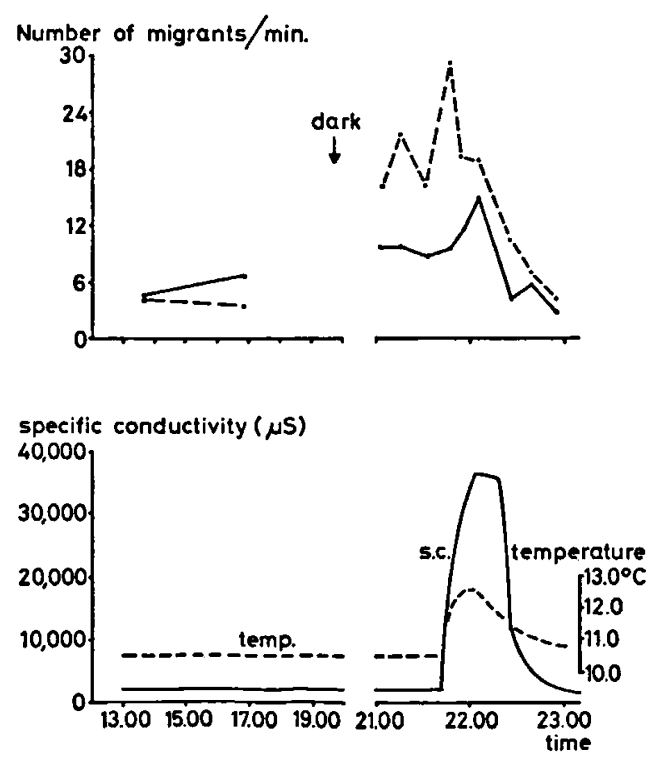

Fig. 27. Influence of a rise in salinity and temperature of the medium on the migratory activity of $G$. zaddachi (25/26 April 1974, population F). The current velocity was kept constant at $3 \mathrm{~V}$ in downstream direction. For explanation see fig. 15, and section V.3 of the text. the temperature rises $1^{\circ}$ to $2^{\circ} \mathrm{C}$ at high tide (see section III, table III, and Dennert \& Van Maren, 1974).

In most of our experiments this change in the water temperature was simulated. In order to investigate the sole influence of a quick rise of the temperature on the activity of $G$. zaddachi, the temperature was varied in the current chamber, while the other factors, viz. salinity and current velocity were kept constant (experiment with population $\mathrm{C}$, fig. 28). The graphs show, that no effect of this quick rise in temperature on the activity of $G$. zaddachi was found.

In an experiment with $G$. chevreuxi (population J, fig. 29) where a quick rise in temperature was combined with a reversal of the current direction (simulation of a freshwater tidal movement), raising the temperature causes an increase of the activity, and only when the temperature drops to the initial value of $7.5^{\circ} \mathrm{C}$ the activity drops to "normal" values.

Although no influences of a quick rise in temperature of the medium could be demonstrated in the case of $G$. zaddachi, a long lasting rise of the temperature has a considerable effect. This has been demonstrated in section IV. 4.

\section{5. Conclusions}

A. Comparison of the behaviour of juveniles and adults.

Considering the origin and the composition of the experimental populations, and the results of our experiments, the conclusion seems to be justified that there is no clear difference in behaviour between juveniles, preadults and adults with regand to their behaviour during the simulation of a tidal cycle. The differences always found in nature between upstream migrants and downstream migrants (Dennert et al., 1969; Girisch et al., 1974) must be explained in another way (see section VI. 2).

B. The trigger for initiating the migratory activity.

The combination of a decrease in the current velocity, followed by a slow current in upstream direction, an increase in the salinity of the medium during the period with low current velocities, and a rise in the temperature caused a significant increase in the activity of both $G$. zaddachi and $G$. chevreuxi. A change in one of the environmental factors mentioned above only, the other factors being kept constant, usually produces an increase in the migratory activity, but less pronounced than 

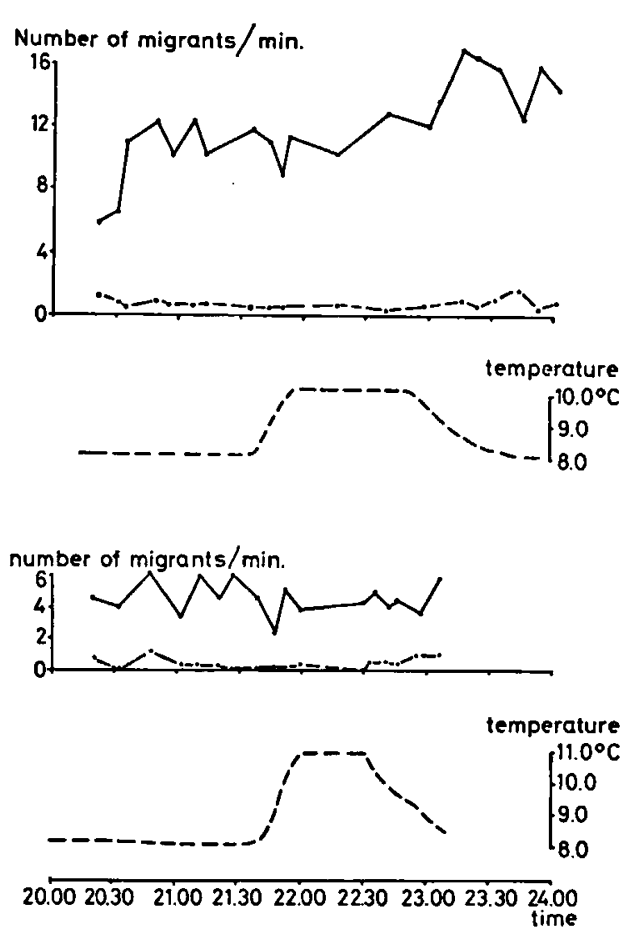

Fig. 28. Influence of a rise in the temperature of the medium on the migratory activity of $G$. zaddachi (population C). The observations were carried out on 29 January 1974 (above), and on 30 January 1974 (below). During the experiments current velocity and specific conductivity were kept constant at $3 \mathrm{~V}$ in downstream direction, and $1250 \mu \mathrm{S}$, respectively. For further explanation see fig. 15 , and section V.4 of the text.

in cases when the combined factors acted in a complete tidal cycle simulation. The master factor causing an increase in the activity is a change in the current velocity and current direction in the way described above.

Increase in activity caused by the sole change in the salinity of the medium always lasted a short time only. The sole influence of a change in the temperature was made probable in the case of $G$. chevreuxi only, in an experiment with rather low current velocities (see section V. 4). In $G$. zaddachi, in experiments with a higher current velocity, no effect of a change in the temperature could be demonstrated.

\section{DISCUSSION}

VI. 1. The migratory activity of G. zaddachi and G. chevreuxi correlated with biotic and abiotic factors

Overlooking our experiments we tend to the conclusion, that the reactions of both $G$. zaddachi and $G$. chevreuxi on the environmental factors investigated here (viz. current velocity, salinity, and temperature, all in the order of magnitude as they occur in nature during a tidal cycle in an estuary), are fundamentally the same.

In our experiments we have established evidence, that the migratory activity of $G$. zaddachi and $G$. chevreuxi is mainly influenced by the current velocity, and that changes in salinity, and sometimes also changes in the temperature of the medium, have an influence on the migration of both species that comes on top of the influence of the current velocity.

The combination of a decrease in the current velocity, followed by a slow current in the opposite direction, a rise in the salinity of the medium, and a rise in the temperature of the medium gives a very significant increase in the activity of $G$. zaddachi and $G$. chevreuxi. Also a change in one, or in two of these factors can give an increase in the activity, but the effect is not so strong, or not so long lasting. As stated above, the
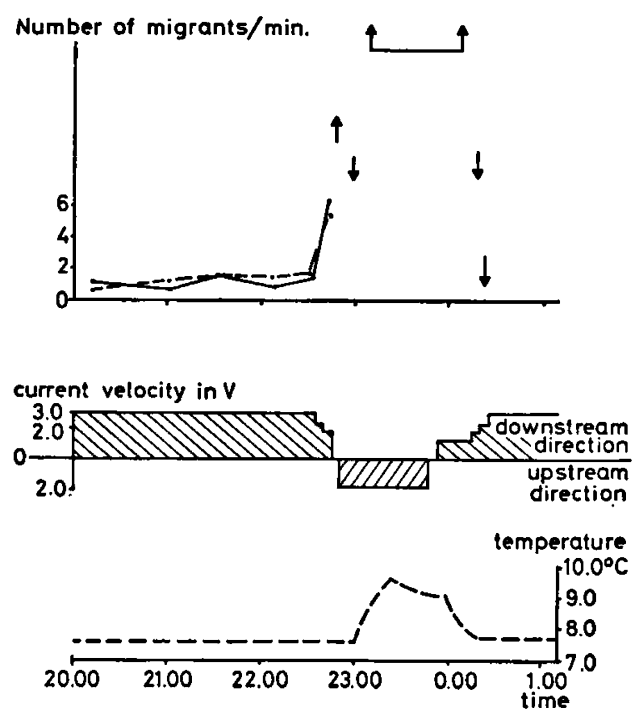

Fig. 29. Influence of a tidal cycle without a rise in the salinity on the migratory activity of $G$. chevreuxi $(18 / 19$ March 1974, population J). For explanation see fig. 15, and section V.4 of the text. 
master factor is a change in the current velocity. So, in situations as found in the middle range of the river Slack (cf. Dennert et al., 1969) where a tidal movement exists without changes in salinity, migration will be induced. In such a situation, changes in the temperature may reinforce the migratory activity. In the estuary, especially at low current speeds, a change in the salinity will be an extra stimulus.

Both species seem to have positive rheotropism; when an animal leaves the substratum it tries to swim against the current. Therefore not only the factors mentioned above, viz. current velocity, salinity, and temperature, but also the particle size of the substratum has an influence on the migratory activity of both species. We have often seen, that animals are washed away from the substratum, and that in this way the majority of the downstream migrants, the so called drifters come into existence.

At the simulation of a complete tidal cycle, particularly $G$. chevreuxi developed a behaviour in which the animals did not swim with the current, or against the current, but up and down in vertical direction. In nature this behaviour will result in a slow transportation of the animals in anadromous direction by the flood current.

The end of the period of activity could not be strictly correlated to any of the varying factors. In all cases however, when a complete flood tide was simulated, the activity of the animals dropped at the end of the flood tide simulation. In nature the result of this phenomenon will be, that upstream migrants will not be transported back in downstream direction after the flood tide.

In section IV. 3 the influence of the food supply on the activity of G.zaddachi is shown. We can freely assume, that in $G$. chevreuxi a similar negative correlation between food supply and activity exists. A shortage of food will force the animals to search actively for new resources. The higher the population density is, the faster the animals will do so. It is therefore understandable, that especially in periods when in nature the population density is high (i.e. shortly after the main reproductive period), peaks in migratory activity are recorded (Dennert et al., 1969; Dennert \& Van Maren, 1974; Girisch et al., 1974).

G. chevreuxi from the Dourduff, whether caught while migrating in anadromous direction (upstream) or while migrating in catadromous direction (downstream), did not show differences in migratory activity in the current chamber (pop- ulation $\mathbf{G}$ and $J$ on the one hand, and $H$ on the other hand).

Still there was a great difference in average body size in these experimental populations, as is to be seen in figs. 4 and 5 . A prudential conclusion may therefore be, that the behaviour of juveniles and preadults on the one hand, and adults on the other hand is similar. In G. zaddachi small differences have been found between the reactions of originally upstream migrants and originally downstream migrants. These differences are, when compared with the points of agreement between the upstreamers and the downstreamers, relatively small.

The behaviour of $G$. zaddachi originating from the river Slack is typical for all brackish water specimens of this species. G. zaddachi originating from the (stagnant) North Sea Canal reacted like Slack specimens on changes in the environmental factors. When we see, that also Chaetogammarus marinus (Leach) living in the eulittoral zone has developed a similar behaviour with regard to changes in environmental factors (Fincham, 1972), we may suppose, that the behaviour of $G$. zaddachi and $G$. chevreuxi as described in the present paper, has in it the basic characteristics of a response mechanism developed in euryhaline Gammaridae. Due to the different environmental factors involved, and the individual capacities of the specimens, the results of this basically the same behaviour will differ.

\section{2. The migration cycle of G. zaddachi and $G$. chevreuxi}

Girisch et al., 1974, supposed that the migratory activity of $G$. zaddachi and $G$. chevreuxi and the migration of other brackish water crustaceans show great conformity.

All the species concerned were supposed to change their reaction on changes in salinity during their lifetime. As a result of our present experiments, when juveniles and preadults are compared with adults, such a change in behaviour need not, and does not exist.

The fact, that in wintertime in the limnic parts of the rivers Slack and Dourduff juveniles and small adults are found, while in the estuary mainly adults in the propagation phase are found, can be explained in a different way than by assuming differences in the reaction on the same changes in the environment during a tidal cycle of juveniles and small adults on the one hand, and adults on 
the other hand. Most probably not a difference in behaviour between juveniles and adults during flood tide, but a difference in behaviour during ebb tide is responsible for the differences found in nature in the distribution of juveniles and adults.

The following considerations can help to explain the fact, that more adults are found in the downstream samples:

- During the winter months very many juveniles and small adults live in the limnic parts of the river Dourduff. The substratum of the bed of the river consists here of gravel and very coarse sand. Since the animals are able to feed on the detritus and algae found here, they need not leave the substratum in search for food (cf. section IV. 3). Hence they are not influenced so strongly by changes in current speed, and have only little chance to become drifters.

- When the animals grow, the cavities between the particles of the substratum may become too small. At the same time a shortage of the food becomes more likely, and a tendency will develop to leave the substratum. In section IV.3 it is shown, that the search for food can initiate the migratory activity.

- Together with the search for food, the adults will show pre-reproductive activity (cf. Lehmann, 1967).

- According to Schwartz (1970) during all kinds of activity the adults have more chance to leave the zone with very low current velocities just above the bottom, than the juveniles have.

- In the limnic part of a river, increase of the activity of the animals above the substratum results in an increase of the drift. In pure freshwater species such as $G$. pulex the reverse may occur, and large numbers of animals may move upstream (Hughes, 1970; Meijering, 1972). In the case of $G$. chevreuxi and $G$. zaddachi, however, the conditions in the limnic part of a river are suboptimal (Girisch et al., 1974). Originally brackish water gammarids lack the ability to swim against the current for a long time; probably the osmoregulation costs too much of their energy. For this reason, another brackish water gammarid, G. tigrinus, is not able to colonize rivers with a low salt content (Schmitz, 1960), while also very strong species like $G$. duebeni have only partly succeeded in penetrating fresh water (Dennert, 1975).

The new hypothesis, that the differences found in nature in the composition of the downstream and upstream catches are caused by differences between juveniles and adults with regard to their drifting properties is not contradicted by the results found in the field (cf. Dennert et al., 1969; Dennert \& Van Maren, 1974; Girisch et al., 1974).

- The samples of anadromous migrants always contained adults, in the river Dourduff the percentage of adults may even be very high. - In the river Dourduff, after the main peak in the migration in anadromous direction, immediately one in catadromous direction starts. The adults found here are part of the migrants that have established themselves only short time before in the limnic part of the river (cf. Girisch et al., 1974).

- According to the old hypothesis, the percentage of juveniles in the samples with upstream migrants was higher than that in the standing crop. There is some evidence, that the number of juveniles in the standing crop was underestimated in our previous work. According to Angelier (1953) the percentage of juvenile $G$. pulex that live in the substratum is rather high. In our dip net catches the smallest animals were underrepresented.

- The tagging experiments (Dennert et al., 1969; Brandse \& Dennert, unpublished) were not too convincing, so the conclusions drawn from these results may not be significant.

Summarizing, the migration cycle of $G$. zaddachi and $G$. chevreuxi seems to be built up in the following way:

Fundamentally the animals show positive rheotropism. Since in the limnic part of the rivers Slack and Dourduff the conditions are suboptimal for both species, the number of drifters, participating in the "constant drift" or in the "behavioural drift" (cf. Waters, 1965), is larger than the number of animals actually moving in upstream direction. So in the limnic part of a river every increase in the activity automatically means an increase in the drift. The differences in way of life between juveniles and adults summarized above, result in an overproportionate contribution of the adults in the downstream catches in the field. The result of all this is, that the limnic parts of the river are gradually depopulated, the smallest animals staying the longest. In the more estuarine parts of the river, juveniles, preadults and adults show the same behaviour during flood tide. As is shown in the present paper, in consequence of 
this behaviour the animals are transported in anadromous direction. So, in the periods with high floods, the limnic parts of the river are populated.

The gradual differences found in the field between the migration cycles of G. zaddachi and $G$. chevreuxi can be explained by the different conditions under which optimal reproduction takes place, and by the fact that $G$. chevreuxi can withstand higher temperatures in the limnic parts of the river Dourduff (Girisch et al., 1974).

\section{ACKNOWLEDGEMENTS}

The authors are indebted to Prof. Dr. J. H. Stock and Drs. F. Peeters for their help in preparing the manuscript, to Dr. S. Pinkster of the Institute of Taxonomic Zoology, Amsterdam, for all the facilities put at our disposal, to Mr. H. Mittelberg for his assistence in constructing the current chamber, to Mr. J. Zaagman for his assistence in making the graphs, and to Direction and Staff of the Station Biologique, Roscoff, France, where the authors received hospitality during part of the work.

\section{LITERATURE}

ANGELIER, E., 1953. Recherches écologiques et biogéographiques sur la faune des sables submergés. Archs Zool. exp. gén., 90 : 37-162.

Cummins, K. W., 1962. An evaluation of some techniques for the collection and analysis of benthic samples with a special emphasis on lotic waters. Am. Midl. Nat., 67 : 477-504.

DENNERT, H. G., 1975. The variability of the dimensions of the merus of the fifth pereiopod in the amphipod Gammarus duebeni Liljeborg, 1852. Bijdr. Dierk., 45 (1): $1-19$.

Dennert, H. G., A. L. Dennert, P. Kant, S. Pinkster \& J. H. STOCK, 1969. Upstream and downstream migrations in relation to the reproductive cycle and to environmental factors in the amphipod, Gammarus zaddachi. Bijdr. Dierk., 39 : 11-43.

DenNerT, H. G. \& M. J. van MAREN, 1974. Further observations on the migration of Gammarus zaddachi Sexton (Crustacea, Amphipoda) in a French stream. Bull. zool. Mus. Univ. Amsterdam, 3 (20) : 157-167.

Fincham, A. A., 1972. Rhythmic swimming and rheotropism in the amphipod Marinogammarus marinus (Leach). J. exp. mar. Biol. Ecol., 8 : 19-26.

Girisch, H. B., J. C. Dieleman, G. W. Petersen \& S. PInxsTer, 1974.The migration of two sympatric gammarid species in a French estuary. Bijdr. Dierk., 44 (2) : $239-273$.

HuGHEs, D. A., 1969. Responses to salinity change as a tidal transport mechanism of pink shrimp, Penaeus duorarum. Biol. Bull., 136 (1) : 43-53.

,- 1970 . Some factors affecting drift and upstream movements of Gammarus pulex. Ecology, 51 (2) : 301305.

LehmanN, U., 1967. Drift und Populationsdynamik von Gammarus pulex fossarum Koch. Z. Morph. Okol. Tiere, $60: 227-274$.
Maren, M. J. van, 1974. Répartition et écologie d'Amphipodes (surtout Gammaridés) dans le bassin et l'estuaire de la rivière du Dourduff (Bretagne). Bull. zool. Mus. Univ. Amsterdam, 3 (22) : 189-209.

Meijering, M. P. D., 1972. Experimentelle Untersuchungen zur Drift und Aufwanderung von Gammariden in Fliessgewässern. Arch. Hydrobiol, 70 (2) : 133-205.

SchmrTz, W., 1960. Die Einbürgerung von Gammarus tigrinus Sexton auf dem europäischen Kontinent. Arch. Hydrobiol., 57 : 223-225.

SCHWARTZ, P., 1970. Autökologische Untersuchungen zum Lebenszyklus von Setipalpia Arten (Plecoptera). Arch. Hydrobiol., 67 : $103-172$.

Stock, J. H., H. NuJssen \& P. Kant, 1966. La répartition écologique des Amphipodes de la famille des Gammaridae dans la Slack et son estuaire. Bull. zool. Mus. Univ. Amsterdam, 1 (3) : 19-30.

Venema, S. C. \& F. Creutzbero, 1973. Seasonal migration of the swimming crab Macropipus holsatus in an estuarine area controlled by tidal streams. Neth. J. Sea Res., 7 : 94-102.

VoBIs, H., 1972. Rheotaktisches Verhalten vom Gammarus pulex, Gammarus roeseli und Gammarus fossarum bei verschiedenem Sauerstoffgehalt des Wassers: 1-32. (Mimeographed report, Landesstelle für Gewässerkunde und wasserwirtschaftliche Planung BadenWürttemberg, Karlsruhe).

WATERS, T. F., 1965. Interpretation of invertebrate drift in streams. Ecology, $46: 327-334$.

,- 1969 . Invertebrate drift - ecology and significance to stream fishes. In: T. G. NorTHCore ed., Symposium on salmon and trout in streams: $121-134$ (H. R. MacMillan Lectures in Fisheries, Univ. Brit. Columbia, Vancouver). 